\title{
Viral Resistance Domain
}

National Cancer Institute

\section{Source}

National Cancer Institute. Viral Resistance Domain. NCI Thesaurus. Code C106581.

A findings domain that captures information regarding the genetics of viral drug resistance. It contains the reference sequence used to validate the observed genetic mutation of interest. 